\title{
Comparing the effects of propofol and ketamine on the emergence agitation of male children undergoing circumcision
}

\author{
Ayşenur Sümer Coşkun * (1)
}

\begin{abstract}
Background: Separation from the family, prolonged hunger, inability to perceive the surgical procedure performed, and feeling pain are among the main reasons for agitation in young children. In operations like circumcision, in which all bodily integrity is disrupted and children cannot make sense of it and feel punished, this agitation increases. The aim of the present study was to compare the effects of propofol and ketamine on the emergence agitation (EA) in children undergoing circumcision.

Result: When the patients were taken to post-anesthesia care unit (PACU), no statistically significant difference was observed between propofol and ketamine groups in the Aono's four-point scale at minute $0(p=0.073)$. In the 5 th minute, it was higher in the ketamine group compared to the propofol group $(p<0.001)$. With Aono's four-point scale, EA diagnosis is made in areas with 3 and 4 points. The average Aono's four-point scale in the ketamine group at the 5 th minute was $3.08 \pm 1.02$. Since the Modified Steward score was $\geq 6$, the time taken was longer in the ketamine group compared to the propofol group $(p<0.001)$.

Conclusion: EA does not only occur in inhalational anesthetics, it is also seen with ketamine. In view of the fact that ketamine can cause EA in children, it should not be used alone in anesthesia. Propofol provides a safe anesthesia. Instead of inhalational anesthesia, where the type of surgery is suitable, anesthesia with propofol infusion should be applied. Further research is required to investigate EA.
\end{abstract}

Keywords: Emergence agitation, Ketamine, Propofol, Circumcision

\section{Background}

Since its introduction in 1960, post-operative early agitation (EA) has been the subject of many studies. It is characterized by behavioral changes, screaming, crying, restlessness, irritability, convulsions, and disorientation during the recovery period after general anesthesia [1]. Although extensive research has been carried out on EA, its reasons have not been fully calrified yet. Among the risk factors associated with the increased incidence of EA, we can name male gender, preschool age, higher preoperative anxiety level, and irregular breathing while

*Correspondence: anur.sumer@gmail.com

Kepez State Hospital, Antalya, Turkey sleeping at the onset of anesthesia [2]. In preoperative anxiety, the type of surgery performed, the personal characteristics of the patient, inadequate relief of pain in the postoperative period, and the anesthetic agent administered are also believed to play a role [3]. A study by Nasar et al. showed that the incidence of EA decreased but did not disappear after sufficient pain control [4]. The sevoflurane, isoflurane, and desflurane elements in halogenated anesthetics are thought to play an important role by changing the child's brain activity and disrupting the balance between central nervous system's neurosynaptic stimulation and inhibition. It is known that sevoflurane is the most frequent culprit agent in pediatric cases with postoperative agitation [5]. However, early postoperative agitation is also observed in intravenous anesthetics. 
Ketamine is frequently used during outpatient anesthesia. N-Methyl-D-aspartate (NMDA) is classified as a receptor antagonist. However, its effectiveness mechanism has not been fully explained yet [6]. The half-life of ketamine is approximately $2 \mathrm{~h}$, so it takes a long time for patients to regain consciousness [7]. Its side effects may include confusion, tension, or delirium [8]. The long halflife of ketamine and its dissociative anesthesia affect the awakening. Screaming, crying, and hallucinations can be witnessed during emergence. In our research, in order to reduce these effects, $0.1 \mathrm{mg} / \mathrm{kg}$ midazolam was administered to the patients in the induction stage. Midazolam is a sedative and hypnotic benzodiazepine and has a short half-life (2-3h) [9].

Compared to ketamine, propofol has a shorter clearance $(0.5-1.5 \mathrm{~h})$ [10]. Propofol provides its hypnotic effects by activating the central inhibitory neurotransmitter gamma-aminobutyric acid (GABA) [11]. It has also been demonstrated that Propofol selectively blocks acetylcholine release in the baso-cortical and septo-hippocampal pathways [12]. Male circumcision is defined as the partial or complete surgical removal of the foreskin of the penis. Before the operation, young children are afraid that their bodily integrity will deteriorate and their newly-discovered genital organs will be damaged. Before the operation, the anxiety levels of the children increase and they usually cry themselves to sleep. This agitation is also reflected in the post-anesthesia period.

Nowadays, approximately 4 million children receive general anesthesia per year, and EA has been identified as an important problem in the post-esthetic care unit (PACU) with a varying incidence rate of 10 to $80 \%$ [4]. It usually ends on its own. During the process, the patient may damage the surgical site and remove the dressing and catheters, and during convulsion, the child may pose physical harm. This situation scares parents too. Unfortunately, there is no effective approach to prevent the development of early postoperative agitation. In the current study, the effects of propofol and ketamine anesthesia on recovery and early agitation in cases undergoing circumcision surgery are compared.

\section{Methods}

For the aim of the retrospective clinical research, approved by the Clinical Research Ethics Committee of Antalya Training and Research Hospital on 17.09.2020, 100 ASA I group children aged 3-10 undergoing circumcision operation between 2017 and 2018 were randomly selected, and their operative records were investigated. Children who had comorbidities and those who used airway devices and neuromuscular blockers during surgery were excluded from the study. Based on the anesthesia method applied, the patients were examined in 2 groups.
Patients who were administered $0.1 \mathrm{mg} / \mathrm{kg}$ midazolam and $2 \mathrm{mg} / \mathrm{kg}$ ketamine for the ketamine group (group K, $n=50)$ and patients who were administered $0.1 \mathrm{mg} / \mathrm{kg}$ midazolam and $2 \mathrm{mg} / \mathrm{kg}$ propofol for the propfol group (group $P, n=50$ ) were included in the study. In both groups, the patients were followed up with spontaneous breathing, and oxygen was provided $2-4 \mathrm{~L} / \mathrm{min}$ through the nasal cannula.

After induction of anesthesia, dorsal penile block was applied to each patient with $0.3 \mathrm{ml} / \mathrm{kg} 0.25 \%$ bupivacaine. For the surgical procedure, there was a 5 -min wait. For patients who required additional sedation, $1 \mathrm{mg} / \mathrm{kg}$ of propofol and $0.5 \mathrm{mg} / \mathrm{kg}$ of ketamine were administered to propofol and ketamine groups, respectively. Nevertheless, patients who could not be immobilized (mobility of the limbs that would impede surgery) and/or those with tachycardia and/or tachypnea as pain symptoms were provided with controlled ventilation using sevoflurane inhalation anesthesia. In patients who were given sevoflurane, medical air in 50\% oxygen and 1 MAC sevoflurane were used subsequently.

Age, weight, and saturation values and ECG findings of all patients were recorded. During anesthesia induction and operation, cough, straining, laryngospasm, bronchospasm, perioperative dysrhythmia, post-operative laryngospasm, bronchospasm, nausea, and vomiting were recorded. During the operation and in the postoperative care unit, the children's body temperatures were maintained around $37^{\circ} \mathrm{C}$ with the help of heated blankets. Aono's four-point scale filled in for early recovery agitation and Modified Steward scores for discharge from the post-operative follow-up room to the ward were evaluated from the anesthesia record paper (Table 1). Emergence agitation was defined to occur when the Aono's four-point scale score was 3 or higher [13]. When the patients were hemodynamically stable and could maintain their own airway, those with a Modified Steward score of 9 and above were transferred to the ward (Table 2). The times spent for this period have been recorded.

All statistical analyses were performed using IBM SPSS version 25.0 (SPSS Inc., Chicago, IL, USA). Continuous variables are presented as mean \pm standard deviation. Categorical variables were presented as numbers

Table 1 Aono's four-point scale (AFPS) for post-operative emergence agitation (EA)

\begin{tabular}{ll}
\hline Asleep & $\mathbf{1}$ \\
\hline Awake but calm & 2 \\
Agitated but consolable & 3 \\
Severly agitated and difficult to console & 4 \\
\hline
\end{tabular}


Table 2 Modified Steward Scale

Consciousness level
Awake
Response to verbal stimuli
Response to touch stimuli
No response
Airway
Coughing or crying on command
Proper airway maintenance
Airway support required
Mobility
Ability to move arms and legs consciously
Moving unconsciously
Immobile

and percentages. Comparisons between groups were made using Mann-Whitney $U$ test for continuous variables and chi square test for categorical variables. The $p$ value of $p<0.05$ was considered statistically significant. Having taken the significance level and effect size of the established hypothesis into account, the sample number was calculated using G-Power 3.1.9.4 program. In our study, based on the means obtained from the propofol group Aons fifth minute $(2.20 \pm 0.53)$ and the ketamine group Aons fifth minute (3.08 \pm 1.02$)$, the effect size was found to be 1.23 (high effect level). To be able to find a significant difference between the groups, while $\alpha=0.05$, $1-\beta=0.95$ (which means the error probability was 0.005 and the power of the test was $95 \%$ ), the sample size in each group was calculated as at least 16. In this regard, the sample size we used in our study seems to be large enough with a sufficient $95 \%$ power.

\section{Results}

In the current study, 100 patients were included. Demographic data including age, weight, and also the duration of anesthesia in the two groups were similar, and no statistically significant difference was found between the groups (Table 3). The average duration of surgery in both groups was determined as $18 \pm 3 \mathrm{~min}$. Nausea, vomiting, spasm, and allergies were not observed in either group.

While $36 \%$ of the propofol group $(n=18)$ needed additional sedation, only $6 \%(n=3)$ of the ketamine group needed additional sedation. It was determined that $22 \%$ $(n=11)$ of the propofol group needed controlled ventilation with sevoflurane. In the metamine group, the need for controlled ventilation was not observed.

In Table 4, Aono's four-point scale scores were compared at minutes 0,5 , and 10 in propofol and ketamine groups. There was no statistically significant difference between the propofol and ketamine groups at minute 0
Table 3 Descriptive statistics of variables

\begin{tabular}{|c|c|c|c|c|}
\hline \multirow[t]{2}{*}{ Variables } & \multicolumn{2}{|l|}{ Propofol } & \multicolumn{2}{|l|}{ Ketamin } \\
\hline & $\begin{array}{l}N(\min - \\
\max )\end{array}$ & $\begin{array}{l}\text { \% or mean } \\
\text { (SD) }\end{array}$ & $\begin{array}{l}N(\min - \\
\max )\end{array}$ & $\begin{array}{l}\text { \% or mean } \\
\text { (SD) }\end{array}$ \\
\hline Age & $50(5-12)$ & $7.34(1.66)$ & $50(5-10)$ & $7.24(1.55)$ \\
\hline Weight & $50(16-38)$ & $25.96(5.49)$ & $50(16-38)$ & $25.52(5.82)$ \\
\hline \multicolumn{5}{|l|}{ Nausea } \\
\hline No & 50 & 100.0 & 50 & 100.0 \\
\hline \multicolumn{5}{|l|}{ Vomit } \\
\hline No & 50 & 100.0 & 50 & 100.0 \\
\hline \multicolumn{5}{|c|}{ Laryngospasm } \\
\hline No & 50 & 100.0 & 50 & 100.0 \\
\hline \multicolumn{5}{|l|}{ Allergy } \\
\hline No & 50 & 100.0 & 50 & 100.0 \\
\hline Heart beat & $50(83-122)$ & $100.78(9.45)$ & $50(95-143)$ & $115.36(11.24)$ \\
\hline Saturation & $50(99-100)$ & $99.80(0.40)$ & $50(99-100)$ & $99.80(0.40)$ \\
\hline \multicolumn{5}{|c|}{ Additional sedation required } \\
\hline Yes & 18 & 36.0 & 3 & 6.0 \\
\hline No & 32 & 64.0 & 47 & 94.0 \\
\hline \multicolumn{5}{|c|}{ Sevoflurane needed } \\
\hline Yes & 11 & 22.0 & 0 & 0.0 \\
\hline No & 39 & 78.0 & 50 & 100.0 \\
\hline
\end{tabular}

when the patients were taken to the PACU $(p=0.073)$. However, at the 5 th minute, it was higher in the ketamine group compared to the propofol group $(p<0.001)$. With Aono's four-point scale, EA diagnosis is made in areas with 3 and 4 points. The average Aono's four-point scale in the Ketamine group at the 5th minute was $3.08 \pm 1.02$. This shows us that the risk of EA in the 5 th minute is the highest in the ketamine group. There was no statistically significant difference between propofol and ketamine groups at the 10th minute $(p=1.000)$.

As seen in Table 5, the time taken for Modified Steward score to reach 6 was found to be higher in the ketamine group compared to the propofol group $(p<0.001)$. A Modified Steward score of 6 and above was set as the prerequisite condition for discharge from the postoperative

Table 4 Aono's four-point scale's (AFPS) comparison between propofol and ketamin groups at minutes 0,5 , and 10

\begin{tabular}{|c|c|c|c|}
\hline \multirow[b]{2}{*}{$\begin{array}{l}\text { Aono's four- } \\
\text { point scale } \\
\text { (AFPS) }\end{array}$} & \multicolumn{2}{|l|}{ Groups } & \multirow[b]{2}{*}{$p$} \\
\hline & $\begin{array}{l}\text { Propofol }(n=50) \\
\text { Mean } \pm \text { SD }\end{array}$ & $\begin{array}{l}\text { Ketamine }(n=50) \\
\text { Mean } \pm \text { SD }\end{array}$ & \\
\hline $0 \mathrm{~min}$ & $1.36 \pm 0.52$ & $1.32 \pm 0.81$ & 0.073 \\
\hline $5 \mathrm{~min}$ & $2.20 \pm 0.53$ & $3.08 \pm 1.02$ & $<0.001$ \\
\hline $10 \mathrm{~min}$ & $2.06 \pm 0.23$ & $2.06 \pm 0.23$ & 1.000 \\
\hline
\end{tabular}

Mann-Whitney $U$ test 
Table 5 Time comparison (in minutes) to reach Modified Steward score $\geq 6$ in propofol and ketamine groups

\begin{tabular}{lll}
\hline & Groups & $\begin{array}{l}\text { Ketamine }(\boldsymbol{n}=\mathbf{5 0}) \\
\text { Mean } \pm \text { SD }\end{array}$ \\
\cline { 2 - 3 } & $\begin{array}{l}\text { Propofol }(\boldsymbol{n}=\mathbf{5 0} \\
\text { Mean } \pm \text { SD }\end{array}$ & $10.44 \pm 3.07$ \\
\hline Time spent to reach Modified Steward score $\geq \mathbf{6}$ & $4.96 \pm 2.77$ & $<0.001$ \\
\hline Mann-Whitney $U$ test &
\end{tabular}

Table 6 Comparison of additional sedation in propofol and ketamine groups according to Aono's four-point scale (AFPS)

\begin{tabular}{|c|c|c|c|c|c|c|}
\hline & \multicolumn{3}{|l|}{ Propofol } & \multicolumn{3}{|l|}{ Ketamine } \\
\hline & \multicolumn{3}{|c|}{ Additional sedation } & \multicolumn{3}{|c|}{ Additional sedation } \\
\hline & $\begin{array}{l}\text { Yes }(n=18) \\
\text { Mean } \pm \text { SD }\end{array}$ & $\begin{array}{l}\text { No }(n=32) \\
\text { Mean } \pm \text { SD }\end{array}$ & $p$ & $\begin{array}{l}\text { Yes }(n=3) \\
\text { Mean } \pm \text { SD }\end{array}$ & $\begin{array}{l}\text { No }(n=47) \\
\text { Mean } \pm \text { SD }\end{array}$ & $p$ \\
\hline Aono's $0 \mathrm{~min}$ & $1.16 \pm 0.38$ & $1.46 \pm 0.56$ & 0.049 & $1.66 \pm 1.15$ & $1.29 \pm 0.80$ & 0.360 \\
\hline Aono's $5 \mathrm{~min}$ & $2.11 \pm 0.32$ & $2.25 \pm 0.62$ & 0.592 & $2.66 \pm 1.52$ & $3.10 \pm 1.00$ & 0.556 \\
\hline Aono's $10 \mathrm{~min}$ & $2.05 \pm 0.23$ & $2.06 \pm 0.24$ & 0.922 & $2.33 \pm 0.57$ & $2.04 \pm 0.20$ & 0.042 \\
\hline
\end{tabular}

Mann-Whitney $U$ test

Table 7 Comparison of Aono's values in propofol groups with added sevoflurane

\begin{tabular}{llll}
\hline & \multicolumn{2}{l}{ Propofol } \\
\cline { 2 - 4 } & \multicolumn{2}{l}{ Added sevoflurane } & \\
\cline { 2 - 4 } & $\begin{array}{l}\text { Yes }(\boldsymbol{n}=\mathbf{1 1}) \\
\text { Mean } \pm \text { SD }\end{array}$ & $\begin{array}{l}\text { No }(\boldsymbol{n}=\mathbf{3 9}) \\
\text { Mean } \pm \text { SD }\end{array}$ & $\boldsymbol{p}$ \\
\hline Aono's 0 $\mathbf{m i n}$ & $1.00 \pm 0.00$ & $1.46 \pm 0.55$ & $\mathbf{0 . 0 0 8}$ \\
Aono's 5 min & $2.00 \pm 0.00$ & $2.25 \pm 0.59$ & 0.135 \\
Aono's 10 $\mathbf{m i n}$ & $2.00 \pm 0.00$ & $2.07 \pm 0.26$ & 0.348 \\
\hline
\end{tabular}

Mann-Whitney $U$ test

care unit to the ward. The time was significantly higher in the ketamine group, with an average of $10.44 \pm 3.07$.

As can be seen in Table 6, Aono's 0-min value in the propofol group was higher in those who did not versus those who did receive additional sedation $(p=0.042)$, and in the ketamine group, Aono's value at the 10th minute was higher in those who received additional sedation compared to those who did not $(p=0.042)$.

As can be seen in Table 7, a statistically significant difference was found between Aono's 0 min and the need for $\mathrm{MV}$ in the propofol group. Aono's 0 min was found to be higher in those who did not need MV compared to those who did $(p=0.008)$.

\section{Discussion}

In the present study, Aono's scores as determinants of EA were found to be higher in the ketamine group compared to the propofol group at the 5th minute in children who were taken to the postoperative care unit (PACU). The difference was statistically significant. Aono's value was set above 3 at 5 th minute and was defined as EA.

Previous studies have generally examined the effects of sevoflurane on EA. In a meta-analysis including 14 studies in which patients undergoing sevoflurane and propofol anesthesia were examined, a total of 560 patients who were anesthetized with sevoflurane and 548 patients who were anesthetized with propofol were investigated. The meta-analysis concluded that propofol anesthesia was shown to result in a lower EA incidence [14]. In line with the meta-analysis study, we also found that the incidence of EA was low in the group anesthetized with propofol. At minutes 0,5 , and 10, the average Aono's value representing EA in the propofol group did not exceed. Emergence from anesthesia with propofol is similar to waking up from a night's sleep, and the patient regains his cognitive functions as the drug leaves the system. In our study, the short half-life and administration of a single dose at the beginning of the operation did not affect the elimination rate of propofol. In the group which was given sevoflurane in addition to propofol, although the Aono's value at minute 0 was found to be lower than that of the sevoflurane group, this value was not sufficient in terms of EA. No EA was observed in the propofol group (Table 7).

In a randomized study of children aged between 2 and 6 undergoing strabismus surgery, Chandler et al. compared TIVA (propofol and remifentanil) and inhalational sevoflurane anesthesia. The study concluded 
that there is a lower incidence of emergence delirium (ED) after TIVA [15]. Similarly, in many studies, propofol has been shown to reduce or prevent EA caused by sevoflurane $[16,17]$.

In another review, the effects of prophylactic propofol dose on the incidence and severity of EA versus placebo in children aged $0-13$ years receiving general inhalation anesthesia were evaluated, and 9 studies including 997 children were investigated. Based on high quality evidence, it has been declared that prophylactic propofol is effective in reducing the incidence and severity of EA in children recovering from general anesthesia [18].

The results of the evaluation of 13 randomized controlled trials (1125 patients) comparing intravenous ketamine in addition to inhalational anesthetics versus placebo for preventing EA in children yielded that the incidence of EA was $14.7 \%$ in the ketamine group and $33.3 \%$ in the placebo group. Being statistically insignificant, it was stated that it is difficult to claim that ketamine is a postoperative EA inhibitor [19].

In our study, there was no need to add sevoflurane to ketamine before the operation, and all patients completed the operation with ketamine anesthesia. As the added ketamine dose increased, Aono's value at the 10th minute was found to be higher in those who needed additional ketamine compared to those who did not $(p=0.042)$. As the ketamine dose increases, the risk of developing EA increases and this difference becomes statistically significant at the 10th minute.

In a study carried out by Hesse et al., during the postoperative EA examination of 626 patients, EEG records in the intraoperative period were kept. Among these patients, it was observed that the groups receiving nitrogen and ketamine were especially associated with PACUDelirium. There is an interaction between anesthetic regimens that involve nitrous oxide or ketamine and the EEG trajectories most associated with PACU-D [20].

Postoperative pain alone is not a risk factor for EA. Even patients who underwent a "painless" procedure under general anesthesia for MRI are reported to have experienced EA [21]. Likewise, Costi et al. compared $3 \mathrm{mg} / \mathrm{kg}$ propofol and seveflurane anesthesia with sevoflurane anesthesia alone using 218 MRI imaging. EA was higher in the group without propofol [22]. In our study, pudendal block was applied to prevent postoperative pain. Surgery was performed after ascertaining that the patients did not feel pain. By doing so, a factor thought to cause EA was eliminated.

The time taken for the Modified Steward score to be 6 and above, as a prerequisite condition for discharge from the postoperative care unit (PACU) to the ward, was found to be longer in the ketamine group compared to the propofol group. Here, the different half-life of drugs is effective. Meanwhile, observation of EA in the ketamine group delayed discharge to the ward. Propofol is a safe drug with a low side effect profile and provides rapid discharge to the ward.

There are limiting factors for our study. Patients who were first added to sevoflurane anesthesia were not excluded from the study. Sevoflurane was used in some patients in the propofol-only group. This group was evaluated among themselves, and Aono's scores were examined. Second, the group receiving only sevoflurane was not established. Propofol and ketamine were evaluated among themselves. Large-scale studies are needed to examine the effects of intravenous anesthetics on EA.

\section{Conclusion}

EA is observed with ketamine. Merely considering that it may cause EA in children, ketamine anesthesia alone should be avoided. Propofol provides a safe anesthesia. Where the type of surgery is appropriate, anesthesia with propofol infusion should be applied instead of inhalational anesthesia. Further research is required to analyze EA.

\section{Abbreviations \\ AFPS: Aono's four-point scale; ASA: American Society of Anesthesiology; EA: Emergence agitation; ECG: Electrocardiogram; ED: Emergence delirium; EEG: Electroencephalogram; GABA: Gamma-aminobutyric acid; Group K: Ketamine group; Group P: Propofol group; NMDA: N-Methyl-D-aspartate; PACU: Post- esthetic care unit.}

\section{Acknowledgements}

Not applicable.

\section{Author's contributions}

All the research is the individual and original work of Dr. Ayşenur Sümer Coşkun. The author read and approved the final manuscript.

Funding

Not applicable.

\section{Availability of data and materials}

The datasets supporting the conclusions of this article are available in the Kepez State Hospital data repository, e-mail: anur.sumer@gmail.com

\section{Declarations}

\section{Ethics approval and consent to participate}

Ethics approval for the research was obtained from the ethics committe of Health Sciences University, Antalya Research and Development Hospital, on 17 September 2020, decision number: 14/6.

Since our research was a retrospective study, participant consent was not obtained. All data has been drawn from historical document scanning. In the criteria of the Ethics Committee of Health Sciences University, Antalya Education and Research Hospital, participant approval is not required for retrospective studies.

\section{Consent for publication}

The author Ayşenur Sümer Coşkun gives consent for publication ın Annals of Pediatric Surgery. 


\section{Competing interests}

The author declares that they have no competing interests.

Received: 20 January 2021 Accepted: 6 October 2021

Published online: 03 January 2022

\section{References}

1. Eckenhoff J, Kneale D, Dripps R. The incidence and etiology of postanesthetic excitement. Anesthesiology. 1961;22:667-73.

2. Reynolds T, Sankaran S, Chimbira W, Phan T, Nafiu O. Severe obesity and sleep-disordered breathing as risk factors for emergence agitation in pediatric ambulatory surgery. J PeriAnesth Nurs. 2018;33(3):304-11.

3. Vlajkovic G, Sindjelic R. Emergence delirium in children: many questions, few answers. Anesth Analg. 2007;104:84-91.

4. Nasar V, Hannallah R. Emergence agitation in children: a review. MEJ Anesth. 2011;21(2):175-84.

5. WangW HP, Gao W, Cao F, Yi M, Chen L, et al. Efficacy and acceptability of different auxiliary drugs in pediatric sevoflurane anesthesia: a network meta-analysis of mixed treatment comparisons. Sci Rep. 2016;6:36553.

6. Mohkamkar M, Farhoudi F, Alam-Sahebpour A, et al. Postanesthetic emergence agitation in pediatric patients under general anesthesia. Iran J Pediatr. 2014:24(2):184-90.

7. Hijazi Y, Bodonian C, Bolon M, Salord F, Boulieu R. Pharmacokinetics and haemodynamics of ketamine in intensive care patients with brain or spinal cord injury. Br J Anaesth. 2003;90(2):155-60.

8. Lalanne L, Nicot C, Lang J-P, et al. Experience of the use of ketamine to manage opioid withdrawal in an addicted woman: a case report. BMC Psychiatry. 2016;16(1):395

9. Johnson T, Rostami-Hodjegan A, Goddard J, Tanner M, Tucker G. Contribution of midazolam and its 1-hydroxy metabolite to preoperative sedation in children: a pharmacokineticpharmacodynamic analysis. Br J Anaesth. 2002;89(3):428-37.

10. Fiset $P$, Paus T, Daloze T, Plourde G, Meuret P, Bonhomme V, et al. Brain mechanisms of propofol induced loss of consciousness in humans: a positron emission tomographic study. J Neurosci Off J Soc Neurosci. 1999;19(13):5506-13.

11. Sanna E, Mascia M, Klein RL, Whiting P, Biggio G, Harris R. Actions of the general anesthetic propofol on recombinant human GABAA receptors: influence of receptor subunits. J Pharmacol Exp Therapeut. 1995;274(1):353-60.
12. Imperato A, Dazzi L, Obinu M, Gessa G, Biggio G. Inhibition of hippocampal acetylcholine-release by benzodiazepines - antagonism by flumazenil. Eur J Pharmacol. 1993;238(1):135-7.

13. Aono J, Ueda W, Mamiya K, Takimoto E, Manabe M. Greater incidence of delirium during recovery from sevoflurane anesthesia in preschool boys. Anesthesiology. 1997;87:1298-300.

14. Kanaya A, Kuratani N, Satoh D, Kurosawa S. Lower incidence of emergence agitation in children after propofol anesthesia compared with Sevoflurane: a meta-analysis of randomized controlled trials. J Anesth. 2014;28(1):4-11.

15. Chandler J, Myers D, Mehta D, Whyte E, Groberman M, Montgomery C, et al. Emergence delirium in children: a randomized trial to compare total intravenous anesthesia with Propofol and remifentanil to inhalational sevoflurane anesthesia. Paediatr Anaesth. 2013;23(4):309-15.

16. Abu-Shahwan I. Effect of propofol on emergence behavior in children after sevoflurane general anesthesia. Paediatr Anaesth. 2008;18(1):55-9.

17. Cohen IT, Finkel JC, Hannallah RS, Hummer KA, Patel KM. Rapid. Emergence does not explain agitation following sevoflurane anaesthesia in infants and children: a comparison with propofol. Paediatr Anaesth. 2003;13(1):63-7.

18. Hoff SL, O'Neill ES, Cohen LC, Collins BA. Does a prophylactic dose of propofol reduce emergence agitation in children receiving anesthesia? A systematic review and meta-analysis. Paediatr Anaesth. 2015;25(7):668-76.

19. Ng KT, Sarode D, Lai YS, Teoh WY, Wang CY. The effect of ketamine on emergence agitation in children: a systematic review and meta-analysis. Paediatr Anaesth. 2019;29(12):1163-72.

20. Hesse S, Kreuzer M, Hight D, Gaskell A, Devari P, Singh D, et al. Association of electroencephalogram trajectories during emergence from anaesthesia with delirium in the postanaesthesia care unit: an early sign of postoperative complications. Br J Anaesth. 2019;122(5):622-34.

21. Bonhomme V, Boveroux P, Brichant J, Laureys S, Boly M. Neural correlates of consciousness during general anesthesia using functional magnetic resonance imaging (fMRI). Arch Ital Biol. 2012;150(2-3):155-63.

22. Costi D, Ellwood J, Wallace A, Ahmed S, Waring L, Cyna A. Transition to propofol after sevoflurane anesthesia to prevent emergence agitation: a randomized controlled trial. Paediatr Anaesth. 2015;25(5):517-23.

\section{Publisher's Note}

Springer Nature remains neutral with regard to jurisdictional claims in published maps and institutional affiliations.

\section{Submit your manuscript to a SpringerOpen ${ }^{\circ}$ journal and benefit from:}

- Convenient online submission

- Rigorous peer review

- Open access: articles freely available online

- High visibility within the field

Retaining the copyright to your article

Submit your next manuscript at $\boldsymbol{\nabla}$ springeropen.com 